\title{
VÍCTOR FRAIZ VILLANUEVA. PROCESO A LA FETE Y A LA ESCUELA REPUBLICANA ${ }^{\alpha}$
}

\author{
Victor Fraiz Villanueva. Process to the FETE and the \\ republican school
}

\author{
Narciso de Gabriel ${ }^{\beta}$
}

Fecha de recepción: 14/12/2019 • Fecha de aceptación: 18/01/2020

Resumen. La represión franquista sobre el profesorado afectó principalmente a quienes tenían una ideología de izquierdas y defendían el laicismo republicano, circunstancias que solían compartir buena parte de los afiliados a la Federación Española de Trabajadores de la Enseñanza, y desde luego sus líderes. Uno de esos líderes fue el pontevedrés Víctor Fraiz Villanueva, que sufrió dos consejos de guerra debido a su actuación política, sindical y docente, uno en 1934 y otro, que lo condujo ante un pelotón de fusilamiento, en 1937. En este trabajo se analizan sus últimos tres años de vida.

Palabras clave: Víctor Fraiz Villanueva; FETE; escuela republicana; represión franquista; depuración del magisterio; consejos de guerra.

Abstract. The repression exerted by the Franco regime on teachers mainly affected people with a left-leaning ideology who defended Republican secularism. This circumstance was quite common among the members of the Spanish Federation of Education Workers, especially among the organization's leaders. One of these leaders was Victor Fraiz Villanueva, a native of Pontevedra, who was court-martialed twice because of his political, union and teaching activities. He was tried in 1934 and again in 1937, and was eventually executed by a firing squad. This article examines the last three years of his life.

Keywords: Victor Fraiz Villanueva; FETE; republican school; repression of the Franco regime; purge of teachers; court-martials.

\footnotetext{
a Agradezco a Aida Terrón Bañuelos y a Helena Zapico Barbeito la lectura del texto y sus observaciones y sugerencias. De sus carencias responde únicamente quien lo subscribe.

${ }^{\text {B }}$ Departamento de Pedagogía y Didáctica. Facultad de Ciencias de la Educación. Universidade da Coruña. Campus de Elviña, s/n, 15071 A Coruña. narciso.de.gabriel@udc.es (iD https://orcid.org/00000002-3630-0908
}

Cómo citar este artículo: Gabriel, Narciso de. «Víctor Fraiz Villanueva. Proceso a la FETE y a la escuela republicana». Historia y Memoria de la Educación 13 (2021): 541-578 
Víctor Fraiz Villanueva nació el 26 de marzo de 1887 en el lugar de Bandeira, perteneciente a la parroquia de Manduas (Silleda-Pontevedra). Era hijo del matrimonio formado por Manuela y Víctor, ambos maestros. Muy joven todavía, emigró a Cuba, donde coincidió con su tío, Vicente Fraiz Andón, profesor en la Escuela Normal de La Habana. De vuelta a Galicia, cursará estudios de magisterio en la Normal compostelana, de la que también fue director su tío Vicente. ${ }^{1}$

La primera escuela que desempeñó fue la de Ponte Caldelas (Pontevedra), donde promovió el asociacionismo del magisterio, formó un grupo de Boy Scouts, ejerció el periodismo -fundó primero El Explorador de Puente Caldelas, de vida efímera, pues solo se publicó el primer número, y luego El Heraldo de Puente Caldelas- y se casó con Placeres Castellanos en 1911. Posteriormente ejercerá la profesión en otras escuelas, como las de Vilaza (Gondomar) y Coia (Vigo), localidades en las que continuará desarrollando una intensa actividad periodística -merece destacarse su colaboración en la revista Escuela Vivida- y cultural, y tendrá una notable proyección sindical y política, particularmente en Vigo, que será donde nos lo encontraremos.

Centraremos nuestra atención en su trayectoria como maestro y miembro de la Federación Española de Trabajadores de la Enseñanza (FETE) durante los años comprendidos entre 1934 y 1937, y utilizaremos como principales fuentes las dos causas a que fue sometido por la justicia militar y el expediente de depuración profesional.

\section{LOS SUCESOS REVOLUCIONARIOS DE 1934}

El 18 de octubre de 1934, a las 13 horas, se presentó la policía en el domicilio de la familia Fraiz-Castellanos, situado en el primer piso del número 62 de la calle Tomás Alonso de la ciudad de Vigo, para comprobar si en él había «armas o documentación» relacionadas con

\footnotetext{
1 Estas breves notas biográficas están tomadas básicamente de Emilio Garrido Moreira, Víctor Fraiz. Vida e asesinato dun mestre exemplar (Santiago de Compostela: Fundación Luis Tilve, 2002), y Anxo Serafín Porto Ucha, Historias de vida. O maxisterio pontevedrés na II República, Guerra Civil e Franquismo (Ponteareas: Alén Miño, 2003), a quienes remito para conocer la historia del personaje que nos ocupa. Garrido Moreira reproduce una carta (p. 183), depositada en el Archivo Histórico Nacional, en la que nuestro protagonista subraya la dilatada trayectoria docente familiar: «Mi abuelo fue maestro durante 50 años. Fueron maestros mi padre y mi madre. Tengo tíos, hermanos, primos y parientes maestros hasta el número de 32 ».
} 
el «pasado movimiento revolucionario». Practicado el correspondiente registro, se encontró abundante correspondencia de la FETE, dirigida a su presidente, Víctor Fraiz; un reglamento de la Asociación de Trabajadores de la Enseñanza (ATE), que suponemos sería la de Vigo, de la que Fraiz fue presidente y secretario; una carta de Isabel Domínguez, esposa de un maestro de la Illa de Arousa (Pontevedra), y otra de Vicente M. Pérez, sindicalista y maestro en el municipio coruñés de Mesía, así como recibos, circulares, carnés, listas de afiliados y de suscritores y un registro de contabilidad de dicha asociación. De todo ello se hizo cargo la policía. ${ }^{2}$

Las supuestas armas no aparecieron, pero la policía recibió una confidencia según la cual, cuando los agentes se disponían a entrar en el domicilio de los sospechosos, un hijo del matrimonio, Vicente, de catorce años, había entregado a Julia Quietan, sirvienta en la casa contigua, a través de una ventana que daba al patio, un paquete del que se sospechaba pudiese «contener materia delictiva». Llamada la sirvienta a declarar, afirmó que efectivamente el mencionado joven, conocido como Perino, le hizo entrega de dos pistolas y un cargador, pidiéndole que las escondiese "porque lo iban a matar» (f. 3). Las escondió en el establo, y así se lo confesó a su ama, Ramona Vidal, que la conminó a devolverlas a sus propietarios, por lo que tuvo que hacerse de nuevo cargo de ellas la madre de Vicente, acompañada de otro de sus hijos, de nombre Ramón y trece años de edad.

A partir de aquí se suceden los interrogatorios policiales, en los que Ramón admitió -al menos eso es lo que se hace constar en la transcripción- haber acompañado a su madre a la casa de los vecinos para hacerse cargo de "una cosa», cuya naturaleza desconocía, que la sirvienta fue a buscar al establo; Vicente negó los hechos que se le imputaban, y lo mismo hizo su madre, que atribuyó la denuncia a rencillas con el vecino, y únicamente admitió que en casa había habido una «pistola detonadora», cuyo propietario era Manuel de Castro, que se

\footnotetext{
2 Archivo Intermedio de la Región Militar del Noroeste. IV Tribunal Militar. Jurisdición de Tierra (Ferrol) (en adelante, AIMNOR), Causa 376/34, Fondo Pontevedra, Caja 182, folio 2. Siempre que no se especifique otra fuente, deberá entenderse que las citas de este primer apartado proceden del sumario de esta causa, al que nos referiremos especificando entre paréntesis en el cuerpo del texto los folios a los que corresponden, por lo menos cuando tengan una cierta entidad (f. 2).
} 
la había prestado para "las carreras de bicicletas del año pasado», y que habían escondido para evitar que los niños jugasen con ella, desconociendo adonde había ido finalmente a parar; Ramona, por el contrario, confirmó la declaración de la sirvienta, a quien censuró su proceder. Por su parte, Víctor Fraiz manifestó que:

únicamente hace tiempo tuvieron una pistola detonadora que adquirió el declarante para dar las salidas en las carreras de bicicletas efectuadas el año último y cuya pistola fue ocupada por la Policía hace varios meses a su hijo Víctor, que le fue devuelta más tarde sin que desde entonces haya vuelto a tener noticias de su paradero y que el mismo muchacho era muy dado a andar con esas pistolas detonadoras ya de su propiedad o de la de algún amigo suyo, añadiendo que la Policía que recogió a su hijo la pistola [de la] que queda hecho referencia fue la Policía gubernativa y estuvo depositada el arma en esta Comisaría (f. 4 v).

Enterado de los hechos, el comandante militar de Vigo encomendó a José Pavón Rodríguez, teniente de Infantería, la instrucción de la causa, advirtiéndole que quedaban a su disposición Víctor Fraiz y Placeres Castellanos, ambos encarcelados -el primero en el cuartel de San Sebastián, por no haber espacio en la cárcel del Partido-, y sus hijos Vicente y Ramón, que permanecían en libertad debido a que eran menores de edad. De modo que entre el 19 y el 21 de octubre prosiguieron los interrogatorios -ahora ante la justicia militar -, que se hicieron extensivos a otras personas a las que no haremos referencia por no aportar información relevante para nuestro propósito.

Los hijos solamente reconocen la existencia de la pistola detonadora, con la que les gustaba jugar y que Vicente había extraviado, y Ramón niega haber acompañado a su madre a la casa de los vecinos para hacerse cargo de las armas, y afirma que no puede haber contradicción entre lo que ahora afirma y lo que figuraba en el atestado policial, porque en la comisaría nadie le había preguntado nada al respecto. Placeres Castellanos y Julia Quietan también confirman sus declaraciones; a esta última el juez le presenta una pistola, un cargador y una funda para comprobar que es capaz de identificar tales objetos, que eran los que decía le habían sido entregados por Vicente. Con el propósito de aclarar las 
contradicciones entre unas y otras declaraciones, se hicieron sendos careos entre Julia y Placeres y Julia y Vicente, sin que se consiguiese despejar ninguna incógnita por ratificarse cada parte en sus posiciones y carecer de testigos.

En todo caso, y aun reconociendo que las diligencias por él practicadas no habían conseguido probar los hechos, el 21 de octubre el juez acordó decretar el procesamiento y prisión de Víctor Fraiz por el presunto delito de tenencia ilícita de armas. Aunque el comandante militar también había puesto a su disposición a Placeres Castellanos, lo cierto es que solamente resultó procesado el maestro, que solicitó, sin éxito, la revocación del procesamiento.

Al día siguiente se interrogó al procesado, que se describía así: «estatura un metro seiscientos treinta milímetros, cara redonda, pelo negro, barba poca, nariz regular, ojos garzos». Al ser preguntado si sabía el motivo de su procesamiento dijo desconocerlo, por lo que el juez se vio obligado a comunicárselo, aunque lo hizo en términos distintos a los utilizados la víspera: la tenencia ilícita de armas será sustituida ahora "por figurar como uno de los dirigentes del movimiento sedicioso llevado a cabo en la pasada huelga revolucionaria» (f. $17 \mathrm{v}$ ). A este respecto, la prensa derechista advertía que eran muchos los maestros directamente implicados en la tentativa revolucionaria, y más todavía los que habían contribuido a suscitarla con sus enseñanzas de carácter subversivo, por lo que urgía una depuración en profundidad del magisterio. ${ }^{3}$

El interrogatorio se centró en su condición de dirigente sindical. De hecho, uno de los policías que registraron su domicilio declaró que lo habían hecho por ser «dirigente de la Asociación de trabajadores de la enseñanza e infundir sospechas» (f. $15 \mathrm{v}$ ), y en el registro se encontraron dos cartas, a las que ya hemos aludido, que ponían de manifiesto esta circunstancia y en torno a las cuales se aglutinarán, como veremos, la mayor parte de las indagaciones judiciales.

\footnotetext{
3 Francisco de Luis Martín, Historia de la FETE (1909-1936) (Madrid: Fondo Editorial de Enseñanza, 1998), 185-187. El autor analiza la implicación de la FETE en estos sucesos, que fue importante, aunque no tan masiva como algunos sectores denunciaban. Según Mariano Pérez Galán, estaría relacionado con los sucesos revolucionarios aproximadamente el 2\% del magisterio asturiano. Véase, La enseñanza en la Segunda República (Madrid: Biblioteca Nueva, 2011), 262.
} 


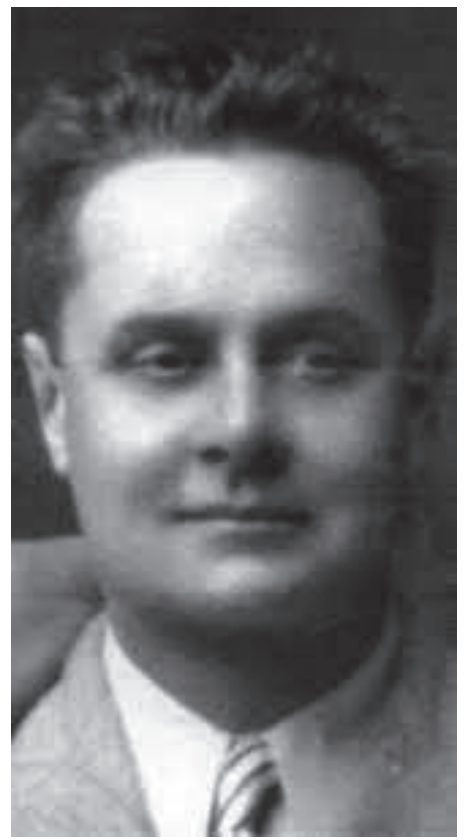

Imagen 1. Víctor Fraiz Villanueva

Una de las cartas había sido escrita el 11 de octubre de 1934 por Isabel Domínguez, casada con Antonio Morales Belmonte, maestro de la Illa de Arousa. Al rumorearse que en la isla se había proclamado el «comunismo libertario», se había presentado la fuerza pública «dando leña en un pueblo pacífico» y deteniendo a muchas personas, entre ellas a su marido, por lo que solicitaba a Fraiz ayuda para ella y sus seis hijos. ${ }^{4}$

\footnotetext{
4 El Partido Socialista de la Illa de Arousa decidió convocar el 7 de octubre de 1934 una huelga general, de carácter pacífico, que se unía a las ya declaradas en Asturias y otros lugares. Concluida la asamblea en la que se tomó tal decisión, los asistentes se dirigieron a una taberna para confraternizar, y fue el propio tabernero quien propuso proclamar la «República Federal da Illa de Arousa», remedando así la proclamación del Estat Català por Lluís Companys el día anterior. La atmósfera revolucionaria, los agravios sufridos por la isla y el calor del vino propiciaron la aprobación de la propuesta y que incluso se barajasen los nombres de algunos miembros del futuro gobierno. La fuerza pública desembarcó en la isla y reprimió con dureza el afán secesionista y revolucionario de sus habitantes, deteniendo a algunos, como fue el caso de Antonio Morales y los integrantes del futuro "gobierno provisional». Véase http://pandulleiros.blogspot. com/2012/08/republica-independente-por-un-dia.html; los autores del blog remiten a Xoán Dopico y Xosé Lois Vila, Historia da Illa de Arousa (Cambados: Concello da Illa de Arousa-Caixanova, 2007). Sobre la repercusión en Galicia de los sucesos de 1934 puede consultarse Emilio Grandío Seoane, A Segunda República en Galicia. Memoria, mito e historia (Vigo: Nigratrea, 2010), 175216, y Xosé Manuel Cid Fernández, Educación e ideoloxía en Ourense na II ${ }^{a}$ República.
} 
Este explicará en el interrogatorio policial que la misiva obedecía a su condición de presidente de la ATE, asociación a la que estaba afiliado el maestro de Arousa, con quien no tenía, por lo demás, amistad ni siquiera trato.

La otra carta estaba datada en la misma fecha y su remitente era Vicente M. Pérez, maestro de Cumbraos (Mesía) y delegado por Galicia en el comité nacional de la FETE. Le comunicaba que había sido destinado a Antequera (Málaga), por lo que

sobre ti recae plenamente el cargo y responsabilidad de delegado al C.N. de las secciones de la Región, que tú con tanto entusiasmo y pericia sabes desempeñar. A la vez se lo comunico a todas las secciones.

También pongo en tu conocimiento, aunque quizás ya lo sepas, que el compañero Ángel Mato, a quien conocías, ha sido asesinado por la fuerza pública el día 6 del actual en Ferrol cuando marchaba a la cabeza de un grupo de obreros revolucionarios, y arrastrado después hasta desfigurarlo. ¡Pobre Mato! Tendría sus errores y equivocaciones, pero han quedado bien lavados con su sangre vertida tan valientemente. No olvidéis a su compañera y a cuatro hijos que deja en la miseria. En Asturias y en Madrid también los maestros se han conducido valientemente. Los de Lugo han sido y son muy perseguidos; la cárcel está siempre abierta para ellos. Luchad con entusiasmo y apretad las filas que la reacción quiere aniquilarnos (f. 7).

El maestro al que se alude era Ángel Mato Peña, destinado en la escuela de O Seixo (Mugardos) y destacado militante socialista, así como director del periódico El Obrero. Sobre su muerte circulaban varias versiones, según afirmaba El Pueblo Gallego -diario editado en Vigo por Manuel Portela Valladare- el 10 de octubre, después de haber faltado cuatro días a la cita con sus lectores debido precisamente a la huelga revolucionaria que afectó a la ciudad olívica. El diario se hacía eco de la versión oficial -el estado de guerra imperante tampoco invitaba a discrepar de las autoridades-, que decía así. El 6 de octubre, «un grupo de

Organización e acción socioeducativa do Maxisterio primario (Santiago de Compostela: Andavira, 2010), 127-132. 
revoltosos» pretendía destruir un transformador eléctrico, situado a la entrada del Arsenal militar de Ferrol y custodiado por dos guardias municipales, con el propósito de dejar la ciudad a oscuras y asaltar la comisaría de la policía. Entre ellos figuraba Mato, que, pistola en mano, intentó desarmar a los dos guardias. Al resistirse estos, «el maestro disparó hiriendo a los guardias, que repelieron la agresión, cayendo al suelo aquel». Fue conducido a la Casa de Socoro -versión que discrepa de la reproducida en el párrafo anterior-, donde ingresó cadáver, y enterrado al día siguiente.

Preguntado Fraiz por su relación con Vicente M. Pérez, respondió que se trataba efectivamente del delegado de la FETE en el comité nacional, del que él era suplente, por lo que le comunicaba su traslado para que se hiciese cargo de la delegación. A las preguntas de «si tenía conocimiento del movimiento revolucionario y si la Federación Española de Trabajadores de la Enseñanza sostenía relaciones con el comité revolucionario» contestó negativamente (f. 18), y en el turno que se le concedió para ampliar sus declaraciones

dijo que de ninguna manera podría figurar, ni tener relación alguna con el actual movimiento revolucionario, ya que, como tal educador conoce perfectamente la Ley y trata de cumplirla estrictamente.

Que no tiene ni ha tenido nunca armas de ninguna clase en su poder ya que por ser profesor solo quiere operar con las armas de la cultura y de la educación. Que prueba estas afirmaciones con el hecho de haber sido registrado en la calle durante estos días por la fuerza pública con resultado negativo y con los agentes de la Autoridad que en aras del cumplimiento de su deber hicieron un minucioso registro en su casa, siendo materialmente imposible que haya quedado lugar alguno que no hayan registrado, ni que haya salido nadie de casa en aquellos instantes sin ser visto por la fuerza pública que rodeaba el edificio (f. $18 \mathrm{v}) .^{5}$

\footnotetext{
5 Fraiz parece referirse aquí a las declaraciones de algunos de los autores del registro, según los cuales, al llamar a la puerta, les abrió Placeres, que fue avisar a su marido, «y en ese tiempo pudo sacarse el paquete con armas a que se refieren anteriores actuaciones» (f. $15 \mathrm{v}$ ).
} 
Concluidos los interrogatorios, el instructor remite un resumen del sumario al auditor de guerra, que considera necesario ampliar las indagaciones. Para ello ordena que se registren los domicilios del maestro de Arousa y del trasladado a Antequera al objeto de comprobar si en ellos existe correspondencia con el procesado, y que se realicen las diligencias que procedan en función del resultado de dichos registros.

En cumplimiento de lo ordenado, el juez se presenta en Arousa, pero allí le comunican que Antonio Morales había sido trasladado a una localidad de Granada. Una vez comprobado que su destino era la escuela del pósito marítimo de Almuñecar, se solicitó mediante el correspondiente exhorto que el juzgado de Motril se encargase de realizar el registro. Así se hizo el 30 de noviembre, sin que apareciese ninguna carta firmada por Víctor Fraiz, aunque sí tres documentos relacionados con el Partido Socialista y con los sucesos revolucionarios.

El primero es un acuerdo adoptado por la Agrupación Socialista de la Illa de Arousa el 29 de julio de 1934, escrito en una cuartilla con el membrete de la agrupación y firmado por su presidente, A[ntonio] Morales. A propuesta de este, se acordó lo siguiente en relación con la próxima celebración de la fiesta San Roque: si «es religiosa oponerse a ella y considerar ofensivo que [se] solicite apoyo a nuestros afiliados», y si «es popular, entonces debe estar controlada por esta Organización y su programa discutido en Asamblea y que tenga lugar en día que no haya ninguna fiesta religiosa» (f. 68). Laicismo estricto, por tanto.

El segundo es una carta dirigida a la esposa de Morales el 25 de octubre de 1934. Está firmada por Maximino Portela, presidente de la Casa del Maestro de Pontevedra, y por Ameijeiras Cerviño, secretario de la Asociación Provincial, que le comunican las acciones desarrolladas por los compañeros del maestro detenido para conseguir su libertad. Esta seguramente se produciría al día siguiente, en virtud de las gestiones realizadas por el diputado José López Varela:

Esta tarde el referido diputado, Sr. López Varela, y los que subscriben, en representación de la Provincial y de la Casa del Maestro, hemos visitado a su marido en el Barco donde se halla en Marín. A dicha visita nos acompañó el $2^{\circ}$ comandante de la 
Base, y créanos, señora, que su esposo, que ya está en libertad a esta hora, estuvo en el Barco perfectamente (f. 62).

El tercer documento es también una carta procedente de la Casa del Maestro de Pontevedra, suscrita por José Meis y dirigida a la misma persona en la misma fecha. Su intención es tranquilizar a Isabel, a la que se informa del estado de su esposo, que muy pronto sería puesto en libertad y podría tomar posesión de su nueva escuela en Almuñecar. "Ayer he ido a visitarle al puntón [pontón] "Minerva”, en el que se halla con otros 29 detenidos sociales». La visita lo reconfortó, "y me manifestó que allí los trataban bien y que lo pasaban alegres y contentos (relativamente, claro está)»(f. 64). Meis volvería a visitarlo el día en que esto escribía y se despedía de la señora ofreciéndole los respetos y servicios de los compañeros de su marido. ${ }^{6}$

En el caso de Vicente M. Pérez, el registro realizado en su domicilio de Antequera no permitió localizar ningún documento comprometedor. Reconocía haberle escrito una carta a Fraiz por ser este su suplente en el citado comité nacional de la FETE, y al serle mostrada por la policía matiza que la había escrito «en un momento de ofuscación», motivado por la muerte de un compañero, y que «si en ella se deslizaban algún concepto o frase molesta o despectiva para la fuerza pública, se retracta de ello por ser producto de dicho momento» (f. $32 \mathrm{v}$. y 33 ).

Una vez practicadas las diligencias ordenadas por el auditor, el juez le remitió un resumen de las mismas, en el que hacía constar que las cartas dirigidas a la esposa de Antonio Morales no contenían materia delictiva. Y el auditor, considerando que la comisión del delito de «tenencia ilícita de armas» no aparecía "comprobada», acordó, con fecha de 21 de diciembre de 1934, sobreseer provisionalmente la causa y ordenar la inmediata puesta en libertad del procesado.

\footnotetext{
6 Fueron numerosos los maestros y profesores encarcelados en Galicia como consecuencia de los sucesos revolucionarios: tres en A Coruña, otros tantos en Lugo y nueve en cada una de las dos provincias restantes, ascendiendo a 219 en el conjunto del Estado, según registros del propio Fraiz, que cifra en cuatro los muertos, uno de ellos Ángel Mato Peña. A ellos hay que añadir los sancionados, que fueron numerosos: solamente en Asturias se abrieron más de 130 expedientes gubernativos. Para socorrer a sus familias, se creó una comisión, formada en la provincia de Pontevedra por Fraiz, Antonio Vidal, Cesáreo Feijóo y José Meis (Garrido Moreira, Víctor Fraiz, 96-97 y 212-216).
} 
Permanecía incautada, sin embargo, la documentación de la ATE, que de alguna manera también aparecía encartada en la causa. Antes de liberarla, el auditor de guerra de la Octava División Orgánica consideró necesario determinar si dicha asociación «fue objeto de sanción en la citada causa [376/34] o en otro procedimiento con motivo del pasado movimiento revolucionario». Al comprobarse que no había recaído ninguna sanción sobre ella, Víctor Fraiz pudo firmar el recibí de los libros y documentos incautados por la policía.

\section{HISTORIA DE UN FUXIDO}

Si en 1934 la justicia militar decidió finalmente, después de haberlo tenido encarcelado durante dos meses, que no existían motivos para sancionar a Víctor Fraiz, tres años más tarde los militares sublevados acordarán poner fin a su vida. Será ejecutado el 14 de septiembre de 1937, a la siete de la mañana, en las inmediaciones del Castillo de O Castro de la ciudad de Vigo. Cuando lo sacaban de la celda para fusilarlo gritará: "Los caballos de la victoria aplastarán vuestras cabezas».7

Había sido detenido el 27 de febrero de 1937, y en sus declaraciones a las autoridades gubernativas y judiciales reconstruirá sus peripecias desde el 18 de julio de 1936 hasta el día de su detención. ${ }^{8}$ Resumiremos brevemente su trayectoria a lo largo de esos algo más de siete meses, para lo que tomaremos como hilo conductor la declaración realizada el 5 de marzo ante la justicia militar, en la que intercalaremos algunas otras, tanto suyas como de otros procesados e informantes. ${ }^{9}$

El día 18, sobre las ocho de la tarde, se presentó en la Casa del Pueblo de Vigo, y en ella permaneció aproximadamente una hora, observando «una gran efervescencia entre las numerosas personas que allí se encontraban, [y] notando al mismo tiempo un gran descontento entre ellas, debido a la poca decisión de los dirigentes para dar órdenes» (f. 36 v).

\footnotetext{
7 Memorias de Manolo Barros. Autobiografía dun militante comunista (Santiago: Fundación 10 de marzo, 2006), 83.

8 Una versión más detallada puede leerse en Elisa Quintas Alborés, Placeres Castellanos (Vigo: A Nosa Terra, 2008), 19-56.

9 AIMNOR, Causa 29/37, Fondo Pontevedra, Caja 237. Todas las citas que aparecen a partir de aquí corresponden, si otra cosa no se señala, a esta causa.
} 
Sabemos que hubo efectivamente una acalorada discusión entre los dirigentes socialistas sobre si debían o no entregarse armas a los obreros, optándose finalmente por no hacerlo, circunstancia de la que algunos seguramente no dejarían de arrepentirse durante lo que les restaba de vida, que en muchos casos sería muy poco. Al día siguiente, aunque estuvo en la ciudad, no se personó en la Casa del Pueblo, y el 20 se enteró, a través de sus hijos, de que había sido declarado el estado de guerra. La lectura del bando que así lo establecía, realizada por el capitán Carreró, al mando de una compañía de infantería con tambores y la enseña republicana, originó enfrentamientos entre la tropa y los defensores de la legalidad, que ocasionaron un buen número de muertos y heridos. ${ }^{10}$

Persuadido por su hijos, temerosos de que «le pudiera ocurrir algo», se dirigió con ellos al domicilio de Gumersinda Iglesias Pereira, su antigua sirvienta, donde permaneció hasta el día 26, "haciendo una vida completamente normal y sin que tratara, para nada, de ocultarse» (f. 36 v); de hecho, salía frecuentemente de la casa, entre otras cosas para escuchar en compañía de los vecinos las noticias de la radio sobre los sucesos que se estaban produciendo. Gumersinda y su marido, Ricardo Fernández Pérez, serán considerados autores de un delito de auxilio a la rebelión por haberlo acogido en su casa y condenados por ello a quince años de prisión.

$\mathrm{Al}$ enterarse a través de "un individuo desconocido que se le buscaba» (f. $36 \mathrm{v}$ ) y que seguramente sería registrado el domicilio en el que se encontraba, la noche del 26 emprendió camino hacia Camos (Nigrán), adonde llegó sobre las doce de la noche. Pidió albergue al párroco, pero este se lo negó alegando que la fuerza pública había estado buscándolo y registrando varias casas de la localidad, incluida la suya. Así que se vio obligado a internarse en el monte de Fragocelo, en el que permaneció varios días, sin ningún tipo de compañía, alimentándose únicamente de pan y queso.

Dado que el lugar no ofrecía posibilidades de permanencia, optó por dirigirse, siempre a campo través, «al monte conocido por Sillargas» -no

\footnotetext{
10 Carlos F. Velasco Souto, 1936. Represión e alzamento militar en Galiza (Vigo: A Nosa Terra, 2006), 258-263. Para una descripción pormenorizada de los hechos, cfr. Galicia bajo la bota de Franco (Santiago: Alvarellos Editora, 2005), 18 y ss (1ª ed. Paris: Jean Flory, 1936) y Carlos Fernández Santander, Alzamiento y Guerra Civil en Galicia (1936-1939) (Sada: Ediciós do Castro, 2007), I, 317-340.
} 
existe ningún Sillargas en el nomenclátor de Galicia, por lo que tiene que referirse a Cillarga, lugar de la parroquia de Ribadetea (Ponteareas), situado en la sierra del Galleiro-, y allí se encontró a otros hombres que como él andaban escapados, pues para quienes habían tenido algún tipo de compromiso con el régimen republicano, huir era la única forma de evitar la prisión, la tortura y la muerte, penalidades que con frecuencia se padecían en su totalidad. Llegó a este lugar sobre el 10 de agosto y no lo abandonó hasta el 25 de diciembre, y «en dicho tiempo se les facilitó por algunos vecinos de los alrededores diversos alimentos con los cuales fueron atendiendo a su subsistencia, pero sin que para ello obligaran a nadie a que se los dieran, pues lo hacían voluntariamente» (f. 37).

Los fugitivos vivían en cuevas. Una era la llamada Cueva Grande, que acogía a más de cuarenta personas, y las otras eran más bien pequeñas. La ocupada por el maestro y otros cinco huidos era una de ellas y estaba dirigida, al decir de este, por un tal Amador y un tal Abraham, aunque otros huidos no dudaban en atribuir la jefatura al propio Fraiz, en solitario o compartida con las dos personas por él mencionadas.

El 22 de diciembre, un grupo de fuxidos -entre 20 y 30, según el primer atestado de la Guardia Civil, aunque otras fuentes reducen la cifra a 15-, algunos de los cuales iban vestidos de falangistas y otros de soldados, mientras que el resto simulaban estar presos y maniatados, para de esta forma no suscitar sospechas, atracaron una tienda de ultramarinos situada en el lugar de Sampaio -perteneciente a la parroquia de San Xoán do Monte, del municipio de Lavadores, que todavía no había sido integrado en Vigo-, haciéndose con un botín compuesto, entre otros productos, por «conservas, perniles de cerdo, dos cajas de turrón, pañuelos, calcetines, cordones, etc.», según declaró uno de los detenidos, Constante Caride Albizú (f. 27). Mientras estaban abasteciéndose, con los parroquianos encañonados, entró a comprar tabaco un falangista del lugar, Benigno Amoedo Retorta, al que mataron. La muerte seguramente no fue accidental, pues al salir del establecimiento los huidos también mataron a un caballo -o a un burro, que en eso discrepan las fuentes- para que no pudiesen seguirles. Y si no estaban dispuestos a dejar detrás de sí una caballería, menos dispuestos estarían a dejar a quien pudiese avisar a la fuerza pública. 
Tres días después, los de la Cueva Grande invitaron a comer a Víctor y a sus compañeros de refugio -era Navidad-, aprovechando para la ocasión algunos de los alimentos robados. ${ }^{11}$ Nuestro hombre, a quien el mencionado Constante Caride exculpó del atraco y de la muerte producida en el curso del mismo, pero acusó de haberse beneficiado de parte de la comida, advertirá que tampoco había sido para tanto: «cuatro pollos con patatas, pan abundante de trigo, dos vasos de vino y un poco de turrón para los cuarenta y tres que eran, tocando por lo tanto a muy pocos gramos de pollo y siendo ligerísima la comida; que nada de carne de cerdo ni conservas les dieron» (f. $28 \mathrm{v}$ ).

Menos mal que la comida y la bebida estaban tasadas, posiblemente pensarían algunos al oír, concluida la confraternización, los tiros de una batida que se había organizado para capturarlos y los obligó a huir en distintas direcciones. Una vez desalojadas las cuevas, sus perseguidores quemaron lo que en ellas había para dejarlas inutilizadas. Previamente habían matado a Manuel González Fresco, el más famoso fuxido de la zona, a cuyas órdenes querían ponerse algunos de los que decidían echarse al monte, ${ }^{12}$ «obsesionados -declara Fraiz- con las victorias de "Fresco"» (f. 28), aunque, por lo que parece, su actuación fue más bien solitaria. ${ }^{13}$

Fraiz y algunos de sus compañeros emprendieron camino hacia Taboexa (As Neves), de donde era uno de ellos y en donde pasaron dos días en una casa deshabitada. Desde allí se dirigieron a Ourense con la intención de pasar a Asturias o a Portugal, como también hicieron bastantes otros huidos, mas pronto comprendieron que la empresa no sería fácil, por lo que en el alto de Mondariz decidieron volver al monte Cillarga, al que también se referían como monte de A Moura. En esas andaban cuando, creyéndose perseguidos, optaron por dispersarse, quedando él de nuevo en solitario, y al encontrarse con un panadero, a quien preguntó por sus antiguos compañeros, y decirle este que

\footnotetext{
11 En el sumario se dice que la comida se celebró el 25 de diciembre, pero según Xoán C. Abad Gallego podría tratarse del 24 , en cuya madrugada se iniciaron las batidas contra los huidos, que constituyen, como es sabido, el precedente de la guerrilla. Véase, «Manuel González Fresco: Un "fuxido" entre la realidad y el mito», Boletín del Instituto de Estudios Vigueses 9 (2003): 35.

12 Víctor F. Freixanes, «O Fresco». Memoria dun fuxido. 1936 (Vigo: Xerais, 1984).

13 Abad Gallego, «Manuel González Freso».
} 
las cuevas habían sido quemadas por la fuerza pública y el monte estaba bajo una estrecha vigilancia, «decidió el declarante dirigirse hacia Vigo bien por si encontraba refugio o para entregarse a las autoridades ya que le era completamente imposible el continuar aquella vida errante» (f. $37 \mathrm{v})$.

Al llegar a la altura de O Porriño decidió dirigirse a Vilaza (Gondomar), donde había ejercido como maestro. Intentó que le diese cobijo su amigo Ramón Méndez González, pero como se negó a hacerlo tuvo que llamar a la puerta de su cuñado, José Fraga, quien le dio de cenar, le permitió dormir una noche en un alpendre de su propiedad y lo animó a entregarse a las autoridades, «a lo que le repuso el deponente que con ese propósito venía, pero que no quería hacer su presentación en ningún cuartel de la Guardia Civil o Falange, por temor a que pudiera ocurrirle algo, y que pensaba hacerlo en la Comandancia Militar de Vigo». También le mostró una carta "que había recibido de un hijo del deponente que se encontraba detenido en el Lazareto de San Simón» (f. 37 v.). Se trataba, como señala Elisa Quintas Alborés, de Víctor Jesús, ${ }^{14}$ que había sido cruelmente asesinado el 10 de noviembre de 1936, hasta el extremo de que sus hermanas, Milagros y María Consolación, no consiguieron identificar el cadáver en un primero momento. ${ }^{15}$ Nada comenta Fraiz al respecto en la declaración judicial, pues, como es sabido, los vencidos ni siquiera podían llorar a sus muertos, y menos todavía en el escenario que nos ocupa. En todo caso, si la transcripción de sus palabras en el sumario es fiel, sorprende que sitúe al hijo muerto en el Lazareto de San Simón, porque en el supuesto de que él ignorase su muerte cuando llegó a Vilaza, ${ }^{16}$ su cuñado seguro que estaba al tanto de ella y

14 Carlos Oubiña Fernández Cid declaró que la noche del 18 de julio había visto llegar de Madrid a Víctor Jesús en el coche que transportaba el pescado, y que «en unión de otro muchacho, bajó del coche dos o tres maletas, de algún peso, a juzgar por lo que observó el declarante, las cuales dejaron en la casa, y que la misma noche oyó bajar y subir de casa y salir con dirección a Bouzas al fallecido [Víctor Jesús ya había sido asesinado en el momento de realizarse esta declaración] con las maletas, continuando en este ajetreo hasta las tres de la madrugada» (f. 70).

15 Quintas Alborés, Placeres Castellanos, y Porto Ucha, Historias de vida. Manuel, el hijo más pequeño, cuenta en «Memorias dun orfo», publicadas por Quintas Alborés (131-150), que su hermano Vicente, a quien ya conocemos debido a su implicación en los sucesos de 1934, murió - «de forma traicionera», advierte Porto Ucha (160) - en el frente del Ebro en 1938; Ramón, que también nos es familiar, falleció en 1944, cuando estaba cumpliendo el servicio militar, y Salustiano fue prisionero de guerra durante tres años.

16 Su esposa, Placeres Castellanos, que se encontraba en Madrid el 18 de junio del año de desgracia de 1936, tardará algún tiempo en enterarse. Lo supo por medio de un vigués que se cruzó con 
sin duda se lo comunicaría, y porque la memoria familiar explica su decisión de entregarse precisamente para evitar que asesinasen al resto de sus hijos.

La casa del cuñado, convertido ahora en guardia cívico, no resultó muy acogedora -llevaban sin hablarse desde que este y la hermana de Fraiz se habían separado en 1922-, así que a la mañana siguiente optó por huir de nuevo hacia Camos, que había sido su primer refugio. Pasó varios días sintiéndose acosado, andando de un lugar para otro, durmiendo en hórreos y pajares y comiendo lo poco que podía conseguir, cuando no se veía obligado a un ayuno prolongado, que a veces duraba cuarenta y ocho horas.

En la parroquia de Castrelos se encontró con Julio Vilaboa Villar, conocido suyo, albañil de profesión y también huido -será condenado a cadena perpetua-, y con él hizo vida en una casa abandonada durante diez o doce días. Juntos acordaron, después de barajar otras alternativas, entregarse en el consulado de México, a cuyo titular conocía Víctor Fraiz $^{17}$, lo que hicieron el día 27 de febrero de 1937 a las diez de la mañana. El cónsul, una vez realizadas las consultas pertinentes, les hizo saber que no podía acogerlos como refugiados, y les aconsejó que se entregasen a las autoridades, «en la seguridad de que, por habérselo hecho presente así la Autoridad Militar de la Plaza, serían juzgados en justicia» (f. 38). De momento se hizo cargo de ellos la Guardia Civil, que los condujo al cuartel de este cuerpo, en cuyas manos permanecieron seis días con sus correspondientes noches, para ingresar posteriormente en la prisión del Partido. ${ }^{18}$

\section{LA FETE Y EL PARAÍSO DEL PROLETARIADO}

La sentencia del tribunal militar que condenó a muerte a nuestro protagonista está encabezada por tres resultandos. El primero sostiene

\footnotetext{
ella en la Gran Vía y le dio el pésame por la muerte de Víctor Jesús (Quintas Alborés, Placeres Castellanos, 67).

17 Se trataba de Victoriano Miguélez, quien será acusado de ser unos de los responsables de la emisión por Radio Vigo del llamamiento de los trabajadores a la huelga en defensa de la República (Freixanes, «O fresco», 36).

18 La declaración de Víctor Fraiz y su entrega a la Guardia Civil aparece firmada, entre otros testigos, por los embajadores de Uruguay y México (f. 29).
} 
que el Ejército autodenominado Nacional -con mayúscula incluida- había instaurado el 18 de julio una nueva legitimidad que puso fin al gobierno del Frente Popular -configurado «mediante unas elecciones ilegítimas por su forma y origen»- para de esta forma evitar que España acabase convertida en una «colonia soviética». En el segundo se establecía que los partidos del mencionado Frente se servían de los sindicatos y asociaciones por ellos controladas "para inculcar en las masas la utopía de una revolución como medio para conseguir el Paraíso del Proletariado», utilizando con tal propósito todos los recursos a su alcance y aprovechándose de las «inteligencias débiles de los que le[s] rodeaban». El tercer resultando se refiere a quien es reconocido como principal protagonista de la causa 29/37,

VÍCTOR FRAIZ VILLANUEVA, persona de cierta cultura de la que se valió para adquirir una personalidad destacadísima en la política local de Vigo extendiéndose a medida que avanzaba su carrera política a toda la región gallega como lo demuestra el hecho de haber sino nombrado Vocal regional de la Asociación de Trabajadores de la Enseñanza de Galicia, institución amparada e inspirada por los ideales marxistas y de la que él había sido uno de sus fundadores, intervino activamente por inducción en el movimiento revolucionario que en la actualidad padece España, propagando en sus mítines y en sus artículos periodísticos esta revolución que él defendía con el lenguaje duro y cruel que caracteriza la doctrina marxista propugnando los delitos de sangre como único medio para conseguirla al decir ante un micrófono "que debe llegar la sangre a los riegos y quemarse los castillos».- Las doctrinas comunistas que sustentaba fueron llevadas por él no solo a mítines y conferencias sino [que] además olvidándose del respeto a la conciencia del niño, las expuso con todo descaro en la escuela por él regentada de Coya, llegando a prostituir el corazón de sus discípulos, en el aspecto familiar inculcándoles que solo debe subsistir el acato a la madre por ser el padre un elemento secundario y accidental, en el aspecto religioso intentando demostrarles con vulgares manejos la negación de la existencia de Dios, y en el aspecto sexual con doctrinas ab[y]ectas e inmorales propias de la escuela marxista.- Declarado el estado de 
Guerra en la Ciudad de Vigo este procesado huye al monte después de haber estado oculto en casa de los también procesados RICARDO FERNÁNDEZ PÉREZ y GUMERSINDA IGLESIAS PEREIRA, durante ocho días, los que le auxiliaron en la comisión del delito de rebelión proporcionándole la fuga y evitando con ello la acción de la Justicia.- Ya en el monte dirige en unión de otros una partida armada que comete toda clase de desafueros y crímenes (f. 119).

Así pues, los hechos que el tribunal considera probados se refieren a la militancia política y sindical del procesado, al ejercicio de la docencia y a su condición de fugitivo, que ya conocemos. En este apartado nos referiremos brevemente a su historial político, para centrarnos seguidamente en su labor como líder de la FETE.

Según la policía, era un «individuo de ideas extremistas de izquierda y uno de los más destacados y fanáticos revolucionarios de Vigo, peligroso para la Nueva España». Había pertenecido al Partido Autonomista Gallego, ${ }^{19}$ a la Organización Republicana Gallega Autónoma -liderada por Casares Quiroga- y al Partido Socialista, situándose en su ala más izquierdista, pues era "partidario de la tendencia de Largo Caballero y del partido Comunista», ${ }^{20}$ pero ni siquiera en este partido encontraba acomodo, "propendiendo el anarquismo socialista». Debido a su formación cultural y activismo, ejercía una gran influencia sobre los obreros;

19 Se trataba del Grupo Autonomista Gallego, creado en 1930 y del que Fraiz fue secretario, ocupando la presidencia Valentín Paz Andrade. Véase, Justo Beramendi, De provincia a nación. Historia do galeguismo político (Vigo: Xerais, 2007), 797-801.

20 El 31 de octubre de 1933 solicitó el ingreso en este partido: «SALUD: // El que suscribe, Víctor Fraiz Villanueva, casado, Maestro Nacional con ejercicio en esta ciudad y vecino de la calle de Tomás Alonso número 62, compenetrado con los principios y táctica del Partido Comunista, solicita ingreso en el Radio de Vigo a partir de esta fecha. // Y como quiera que mi ideología, neta, netamente marxista y revolucionaria, es harto conocida en Vigo y su comarca, no creo sea necesario darles más datos de mi persona a los compañeros que forman la base, de los cuales soy conocido desde hace tiempo y entre los que deseo laborar por la emancipación del proletariado.// Para más datos os remito esta carta, que mandé a la prensa viguesa y no me ha querido publicar, copia exacta de la que remití a la Agrupación Socialista local pidiendo mi baja.//Y en espera de lo que acordéis a este respecto, queda vuestro y de la causa» (f. 47). Sobre su solicitud de ingreso manifestará reservas, en carta a César Lombardía, Félix Salgado, militante de Trabajadores de la Enseñanza de Ourense (ATEO), por entender que todavía no había asimilado las características de un «bolchevique verdadero», como evidenciaban los «resabios [propios] del intelectual pequeño-burgués» que en él se apreciaban, si bien no dudaba de que llegaría a ser un "verdadero comunista». Víctor Manuel Santidrián Arias, Historia do PCE en Galicia (1920-1980) (Sada: Ediciós do Castro, 2002), 99-100 y 152. 
había participado en mítines con Castelao, Bilbatúa y Osorio Tafall en los partidos judiciales de Vigo, Pontevedra y Tui, y resultado procesado por el tribunal de urgencia como consecuencia de su intervención en otro mitin celebrado en Ourense el primero de mayo de 1934; había sido detenido en varias ocasiones, resistiéndose e insultando a la policía; pertenecía a la directiva de Amigos de la Unión Soviética, y, en fin, «ha tomado parte activa en los sucesos revolucionarios de Julio último como organizador de masas obreras, viéndosele aun a altas horas de la madrugada de un lado para otro, desde la Casa del Pueblo hasta el Ayuntamiento acompañado siempre de un grupo de obreros» (f. 50).

La Guardia Civil dibujaba un itinerario político algo distinto y menos acertado: Partido Republicano Radical, Partido Republicano Radical Socialista y Partido Comunista; confirmaba su implicación en la resistencia al ejército sublevado, arengando a los obreros en este sentido, y subrayaba su participación en la propaganda a favor del Estatuto de Galicia, votado el 28 de junio de 1936, en el curso de la cual, y en un mitin a través de Radio Vigo, había pronunciado una frase que mereció figurar, traducida al castellano, en la sentencia: «debe chegar a sangre ós regos ê qu[e]imar[se] os Castelos» (f. 66), afirmación que sin duda necesitaría ser contextualizada para apreciar su significado, pero ya sabemos que los militares rebeldes y sus acólitos no eran muy dados a contextualizar.

Por lo que respecta a la militancia sindical, el informe inicial de la Guardia Civil, firmado por Francisco González Rodríguez, conocido como El Rabioso, sostenía «que a este maestro se le debe en primer lugar, según tiene entendido el Capitán que suscribe, el Congreso Regional de Trabajadores de la Enseñanza de Galicia», que no solo había combatido la religión católica, consustancial a España, sino el propio régimen republicano, propugnando "otro de República socialista», como demostraba el texto publicado en El Pueblo Gallego el 16 de mayo de 1936, firmado por uno de los ponentes, Roberto Panero Fernández -pertenecía a la asociación de Ourense (ATEO), incorporada a la FETE en 193321-, cuyo recorte aportaba al sumario (f. 31). Este era su inicio:

\footnotetext{
21 Xosé Manuel Cid Fernández ha publicado diversos trabajos sobre la ATEO, entre ellos Educación e ideoloxía en Ourense na II ${ }^{a}$ República. Organización e acción socioeducativa do Maxisterio primario (Santiago de Compostela: Andavira, 2010).
} 
Los trabajadores de la Enseñanza aspiramos a una Escuela que se halle al servicio de la noble idea de la emancipación social. Pretendemos aprovechar la plataforma que nos ofrece la Enseñanza para forjar generaciones rebeldes que en un futuro próximo, cuando la actual juventud revolucionaria haya conquistado el Poder político para la clase productora, sean quienes, sin trabas de ninguna especie, puedan dirigir, en todos sus aspectos, el Estado Socialista.

Panero era consciente de las limitaciones que el «Estado burgués» imponía a los maestros en su actuación escolar, como funcionarios que eran de tal Estado, pero estos, en su condición de «militantes proletarios», disponían de una amplia capacidad de maniobra para combatir «las taras acumuladas» en los cerebros infantiles por siglos de capitalismo, especialmente las de origen religioso. En la sociedad futura sería factible "el respeto absoluto a las conciencias infantiles», pero en la actual había que ser beligerantes: «La Escuela debe ser Socialista y antirreligiosa». No bastaba, por tanto, la escuela neutra defendida por cierto liberalismo: «Necesitamos ser sectarios, intransigentes: porque nos enfrentamos con un enemigo ante el cual la menor vacilación supone derrota». Un enemigo que también combatía la coeducación, otro de los principios defendidos por el sindicalista de Ourense. En una línea similar se pronunciaron otros congresistas, como es el caso de Luis Soto Fernández: el respeto a las conciencias de los niños no debe impedir que la escuela pueda «desintoxicar[las]» de las «incontables supersticiones, falsedades, deformaciones morales, complejos psíquicos y perversidades» adquiridas en la familia, la calle y la sacristía. ${ }^{22}$

El capitán de la Benemérita aporta además un recorte del mismo diario con los perfiles de 14 congresistas, una buena parte de los cuales fueron asesinados. Concretamente, de los cuatro delegados por la zona de Santiago, uno fue "paseado» (Jesús Álvaro López Brenlla), dos fusilados (Fernando Barcia Veiras y Luis Rastrollo González) y el cuarto separado de la enseñanza (José A lonso Puente). ${ }^{23}$ Por lo que respecta a la

\footnotetext{
22 El Pueblo Gallego, 17 de mayo de 1936, 2. Luis Soto nos dejó memoria de su militancia política y sindical en Castelao, a U.P.G. e outras memorias (Vigo: Xerais, 1984).

23 Narciso de Gabriel, "A represión dos mestres republicanos de Muros», Sarmiento. Revista Galego-Portuguesa de Historia da Educación 23 (2019): 287.
} 
provincia de Ourense, Xosé Manuel Cid Fernández destaca la especial incidencia de la represión entre el magisterio afiliado a Trabajadores de la Enseñanza, y lo mismo hacen Anxo Serafín Porto Ucha y Raquel Vázquez Ramil en relación con la de Pontevedra. ${ }^{24}$

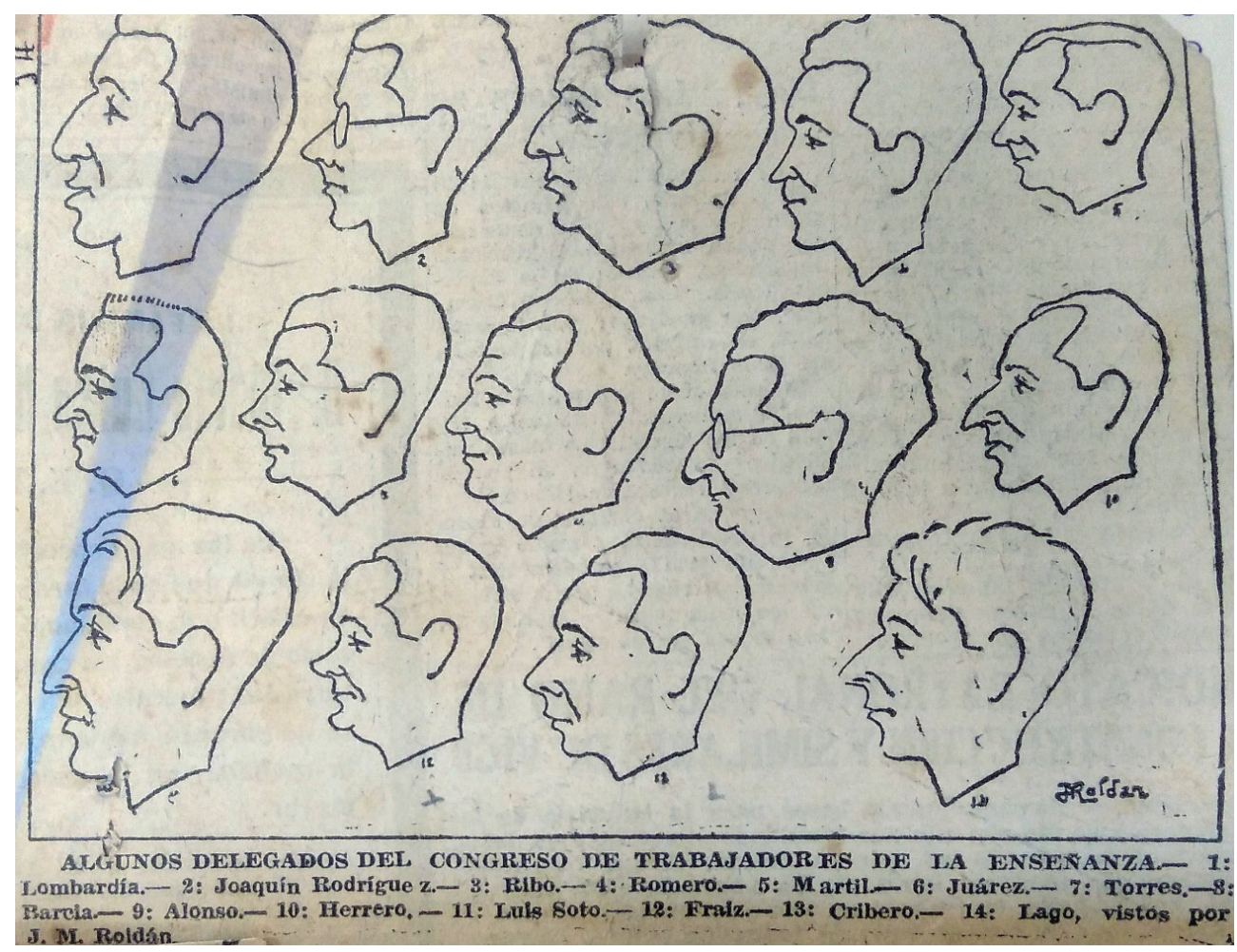

Imagen 2. Retratos de algunos de los asistentes al Congreso Regional de Trabajadores de la Enseñanza (El Pueblo Gallego, 24 de mayo de 1936).

La policía gubernativa también hace referencia a su condición de fundador en Vigo de la ATE, que «casi exclusivamente a él debe su existencia», y recuerda que en octubre de 1934 había sido detenido por ser «uno de los promotores de aquella huelga general» (f. 50 v). Practicado

\footnotetext{
24 «A depuración do maxisterio primario na provincia de Pontevedra (1936-1942)» y «A represión franquista en Ourense: novos argumentos contra a desmemoria na persecución sufrida polo maxisterio", Sarmiento. Revista Galego-Portuguesa de Historia da Educación 21 (2017): 31-72 y 73-99, respectivamente. Véase también Francisco de Luis Martín, La FETE (1939-1982). De la represión franquista a la transición democrática (Madrid: Tecnos, 2009).
} 
un registro en su domicilio se encontraron, como nosotros ya sabemos, documentos y correspondencia relativos a la ATE, e incluso un libro de registro de los miembros de dicha asociación, así como la carta alusiva al asesinato de Ángel Mato Peña, que la policía considera merecedora de ser reproducida íntegramente.

El propio Fraiz reconocía con orgullo, en el momento de entregarse, su condición de dirigente sindical y su participación en el Congreso Regional de Trabajadores de la Enseñanza de Galicia, celebrado en mayo de 1936, cuyas sesiones habían sido presididas cada día por una persona distinta y cuyas discusiones se organizaron en función de lo establecido en una circular firmada por Rodolfo Llopis, ex director general de Primera Enseñanza, que había clausurado el evento con un discurso pronunciado en el Teatro Tamberlick, en el que, además del laicismo, defendió una escuela que «colocara al niño en condiciones de una verdadera libertad» (f. 28).

Aunque en un primer momento estaba previsto celebrar el evento, en el que se constituiría la Federación Gallega de Trabajadores de la Enseñanza (FGTE), entre el 4 y el 10 de mayo, según constaba en la convocatoria hecha pública por Víctor Fraiz como representante de Galicia en el comité nacional del sindicato, finalmente tuvo lugar entre el 17 y el 24 de ese mes. ${ }^{25}$

Fraiz será el encargado de elaborar el proyecto de estatutos de la FGTE, que estaría integrada por las secciones de Trabajadores de Enseñanza entonces existentes: Vigo, Ourense, Lugo, A Coruña, Ferrol y Santiago de Compostela, ${ }^{26}$ e inspirada en los siguientes principios:

A) Contra la guerra y el fascismo.

B) Lucha de clases por la liberación de la clase obrera.

25 El Pueblo Gallego, 2 de abril de 1936, 4. Previamente, el 31 de marzo, hacía saber, a través de este mismo medio, los motivos por los que se había retrasado su realización. Sobre la historia de la FETE en Galicia, y de este congreso en particular, remito a los trabajos de Antón Costa Rico, «Socialismo e educación na Galiza do primeiro terzo do século Xx», en IIas Xornadas de Historia de Galicia, ed. Xavier Castro y Jesús de Juana (Ourense: Servizo de Publicacións da Deputación Provincial, 1986), 135-164., y Escolas e Mestres. A educación en Galicia: da Restauración á Segunda República (Santiago de Compostela: Xunta de Galicia, 1989), 282-290 y 446-453, así como de Garrido Moreira, Víctor Fraiz, en especial las páginas 181-207.

26 El Pueblo Gallego, 19 de abril de 1936, 5. 
C) Escuela única de trabajo útil en toda su amplitud.

D) Por la coeducación y contra la moral sexual burguesa.

E) Acción anticlerical y antirreligiosa con una educación materialista.

F) Por una Galicia marxista, proletaria y autónoma, dentro de su peculiar estructura marinera y campesina. ${ }^{27}$

La propuesta era sin duda radical, y situaba a nuestro protagonista en el sector revolucionario de la FETE, que se hizo con el control de la organización durante el segundo bienio republicano y que tildará de reformista la actuación de sus predecesores, convertidos en acólitos de la Dirección General de Primera enseñanza. ${ }^{28}$ Como afirmaba con contundencia Marcelino Lago, líder de la sección ferrolana, en una de las ponencias presentadas al congreso que nos ocupa, había que prepararse para luchar contra «la burguesía y la carroña que desfilen por el ministerio de Instrucción Pública». ${ }^{29}$ Entre los nuevos dirigentes estatales destacarán los militantes del Partido Comunista, ${ }^{30}$ circunstancia que también se produjo en Galicia, y especialmente en Vigo y Ourense. ${ }^{31}$

27 El Pueblo Gallego, 9 de abril de 1936, 3 (el proyecto continúa publicándose los días 10 y 14 del mismo mes). Una buena parte de las ponencias presentadas, algunas de las cuales pueden leerse en los trabajos ya citados de Costa Rico y Garrido Moreira, estaban en sintonía con estos principios.

28 En un artículo publicado por Fraiz en Escuela Vivida, reproducido por Garrido Moreira (Víctor Fraiz, 162-163), se critica la actuación de los dirigentes del sindicato durante el primer bienio.

29 El Pueblo Gallego, 9 de mayo de 1936, 2.

30 «En esta segunda etapa, que recorre el bienio radical-cedista y el período del frente popular - aunque cabe señalar diferencias entre uno y otro -, la vieja guardia, acusada de reformista y colaboracionista, será desplazada de la dirección de la FETE, sustituida por representantes de la tendencia revolucionaria, líderes de la periferia y también de Madrid que militan bien en el PCE bien en el ala radical largocaballerista del PSOE» (De Luis Martín, Historia de la FETE (1909-1936), 141). Este autor también ha estudiado el período bélico: La FETE en la Guerra Civil española (1936-1939) (Barcelona: Ariel, 2002). Para una visión global de la evolución del asociacionismo del profesorado, véase Aida Terrón Bañuelos, "Coordenadas del asociacionismo profesional de los docentes. Estado de la cuestión en España», Historia y Memoria de la Educación 1 (2015): 93-130, y sobre las relaciones de la educación con el movimiento obrero y el sindicalismo, Aida Terrón y Antonio Viñao, «Educación, movimiento obrero y sindicalismo (España, siglo XX)», Historia de la Educación. Revista interuniversitaria 37 (2018): 69-114.

31 Santidrián Arias, Historia do PC en Galicia, 150-153. 


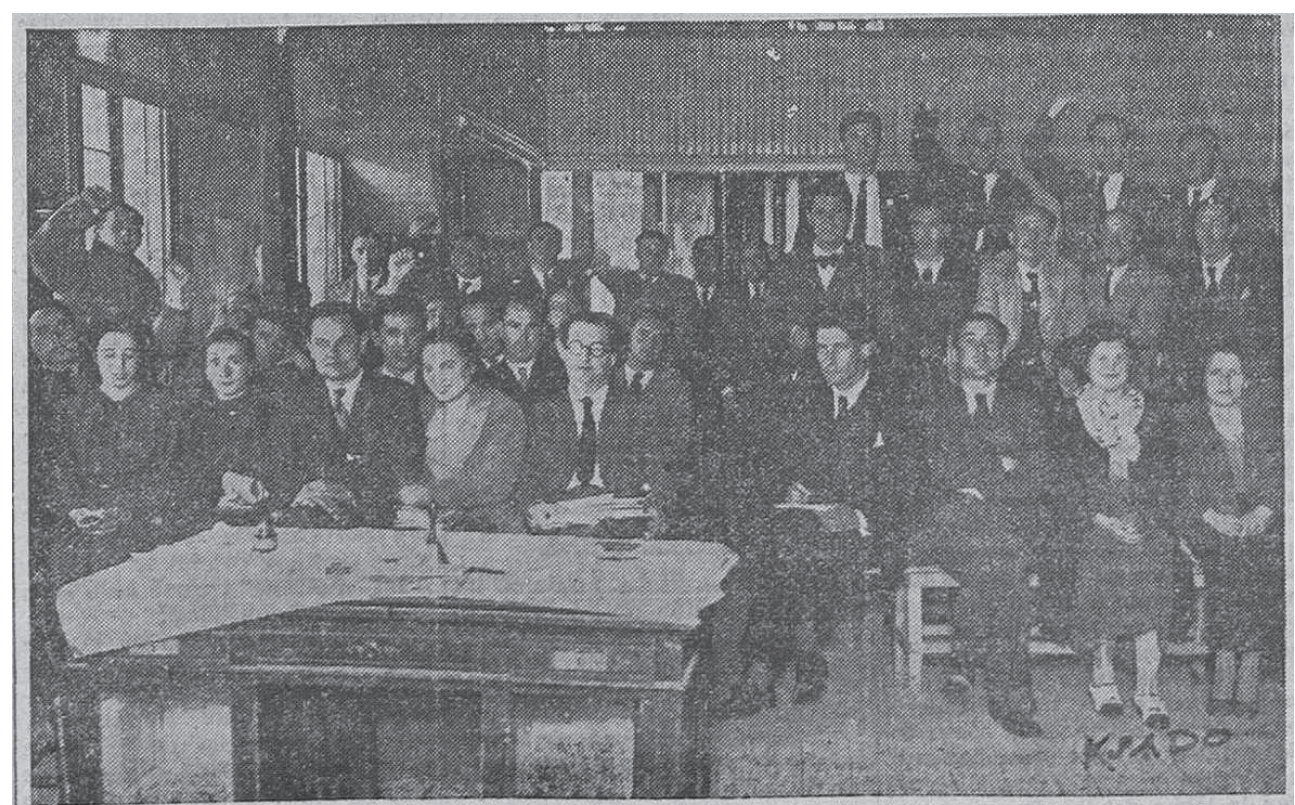

Imagen 3. Congreso Regional de Trabajadores de la Enseñanza. Víctor Fraiz aparece en primer plano y a la izquierda (El Pueblo Gallego, 20 de mayo de 1936).

Prescindiendo de las cuestiones de carácter más bien organizativo, los temas abordados fueron los siguientes: directrices para la elaboración del estatuto del magisterio, bases para una ley de instrucción pública, la escuela y el maestro en Galicia, misión de los trabajadores de la enseñanza en relación con la cultura gallega y estatutos de la nueva organización. ${ }^{32}$ Los debates, muy animados, al decir de la prensa, se desarrollaron en la Casa del Pueblo, aunque uno de los días los congresistas tuvieron que ceder el local a los obreros de la construcción, que estaban en huelga, y trasladarse a la sede de las Mujeres Antifascistas. En la clausura intervinieron, entre otros, un representante de cada uno de los dos partidos hegemónicos en la FETE, el socialista y el comunista.

Por lo demás, tres de los once cargos que se le imputan a Víctor Fraiz en el expediente de depuración a que fue sometido como maestro se refieren precisamente a la FETE y a su actuación sindical: ser directivo, ejercer como delegado en Galicia y «conseguir el envenenamiento del

32 El Pueblo Gallego, 19 de mayo de 1936, 2. 
Magisterio con su triste popularidad».33 La policía viguesa especificaba que tal «envenenamiento» había resultado particularmente intenso en la provincia de Pontevedra, donde «contaba con gran ascendiente, hasta el extremo de conseguir para su causa a maestros de abolengo católico indiscutible». ${ }^{34}$ En su respuesta a los cargos -realizada en la prisión de Vigo-, que fue publicada por el profesor Antón Costa y a la que remito, ${ }^{35}$ se mostrará orgulloso de su dilatada trayectoria sindical, siempre orientada a la defensa desinteresada "de la clase, de la escuela y del niño»-a diferencia de otros, que habían utilizado las asociaciones profesionales como trampolín para el medro personal-, lo que a su entender constituía un mérito y no un cargo. Los depuradores considerarán que el maestro «se muestra socialista recalcitrante» en los descargos y propondrán su separación definitiva del magisterio. ${ }^{36}$

\section{UNA ESCUELA DISOLVENTE}

La justicia militar también prestó especial atención a la actuación del encausado como maestro, a la que se referían los informes oficiales y sobre la que algunas personas estaban particularmente interesadas en testificar.

Ángel Cancelo Miras, militante de Falange, solicitó presentarse en la causa, animado, según sus propias palabras, por un «deber patriótico»-y también por una enemistad manifiesta con el maestro, según argumentará el abogado de este-, para informar sobre «la labor

\footnotetext{
33 Archivo General de la Administración (en adelante, AGA), 32/12882-17. Sobre el proceso de depuración y represión del magisterio existe una abundante bibliografía, recopilada y analizada, entre otras personas, por José Luis Hernández Huerta, «La represión franquista de la enseñanza. Fuentes y bibliografía (1975-2007) para el estudio de la depuración del magisterio nacional», Papeles Salmantinos de Educación 11 (2008): 231-266, y María del Carmen Agulló Díaz, "Amputar, segar, limpar e purificar: a depuración do maxisterio durante o franquismo», Sarmiento. Revista Galego-Portuguesa de Historia da Educación 21 (2017): 9-30.

34 AGA, 32/12882-17.

35 Antón Costa Rico, "A "legalidade" dos franquistas: os procesos de depuración. O caso do mestre Víctor Fraiz Villanueva», Sarmiento. Anuario Galego de Historia da Educación 10 (2006): $289-296$. Los cargos también se reproducen en Lucio Martínez Pereda, Medo político e control social na retagarda franquista (Vigo: Xerais, 2019), 58-59, que alude asimismo a la sanción de que fue objeto su familia como consecuencia de las «responsabilidades políticas» contraídas por el maestro. Para una visión de conjunto sobre el proceso de depuración en la provincia de Pontevedra, véase Anxo Serafín Porto Ucha, Mestras e mestres pontevedreses depurados polo franquismo. Primeiras accións represivas e estudo por concellos no sur da provincia (1936-1942) (Ponteareas: Alén Miño, 2008).
}

36 AGA, 32/12882-17. 
disolvente» realizada por Fraiz en su escuela de Coia (Vigo), a la que habían asistido en 1931 tres de sus hijos, que se vio obligado a retirar de la misma, pues pasaban la «mayor parte del tiempo» entonando canciones revolucionarias, como la Internacional y el Himno de Riego; consideraba a los guardias civiles «asesinos de obreros", y así se lo hizo saber a sus alumnos al pasar una pareja frente a la escuela; propuso a los niños reunir dinero entre la gente del barrio para comprar una máquina de escribir y aprender mecanografía, pero una vez reunida la cantidad necesaria no la adquirió, lo que evidenciaba su «poca moralidad»; y solía llamar al alumnado utilizando el apellido materno, «diciéndoles también que solamente debían reconocer a la madre, ya que el padre podría ser cualquiera, por lo cual deduce el deponente que las ideas que quería inculcarles a los niños eran las del amor libre». Estos «detalles» podían ser corroborados, y si acaso ampliados, por otras cuatro personas, a las que identifica, y que fueron llamadas a declarar por el juez instructor, haciéndolo tres de ellas (f. 68).

Enrique Conde Prior afirma que en la escuela se dedicaba efectivamente «la mayor parte del tiempo» a entonar cantos revolucionarios, lo mismo que Carlos Oubiña Fernández Cid, que calificaba tales cantos de "propaganda marxista envenenadora», mientras que José Cambeiro Martínez venía a decir que el maestro había convertido la escuela en una schola cantorum revolucionaria, añadiendo que, al prescindir de los apellidos paternos, promovía la «destrucción de la familia» (f. 69 y 70).

Todos ellos fueron superados en contundencia por el falangista Jesús del Barrio Lemos, que trabajaba en los servicios de información de la Guardia Civil, por lo que decía conocer en profundidad la labor «disolvente» del maestro. El canto era lo de menos:

También les hacía creer que Lenin les daría caramelos si a él se los pedían, cosa que no podía hacer Dios, y al efecto, cuando se los pedían a Dios, un hijo ya preparado de antemano, les echaba agua, cosa que no ocurría cuando se los pedían a Lenin, pues el citado hijo, les daba los caramelos. ${ }^{37}$ En cuanto a su moralidad, debe hacer constar el declarante que dejaba tanto que desear, hasta el punto de

37 En términos similares se expresaba la Guardia Civil en uno de sus informes, cambiando Lenin por Stalin: sirviéndose de «astucia[s], hacía ver a los niños que si pedían caramelos a Dios no se los daba y en cambio si se los pedían a Extalin $[s i c]$ los obtendrían y cuando los niños se los pedían a 
que es rumor público que había sostenido relaciones amorosas con su propia hija, fruto de las cuales es una niña de seis o siete años; e igualmente también es de rumor público, los actos vergonzosos que ordenaba realizar a las niñas y niños, poniéndolos desnudos, en el tiempo en que regentaba una escuela mixta (f. 91). ${ }^{38}$

En el auto de procesamiento se le acusa de inculcar la ideología marxista a sus discípulos, y en el resumen de las actuaciones elevado al auditor de guerra, el juez instructor hace suyas la mayor parte de las acusaciones de que fue objeto el procesado por parte de los testigos y de las autoridades gubernativas, considerando que su práctica sindical y escolar es lo más «destacado» $\mathrm{y}$ «abominable» de su trayectoria, y «constituye una terrible pesadilla en la memoria de casi todos los vecinos de Vigo que hayan tenido conocimiento de su labor» (f. 102). ${ }^{39}$ Esta dimensión será también la que encabece, como ya sabemos, la sentencia dictada por el consejo de guerra.

En el expediente de depuración figuran dos cargos de esta naturaleza: imprimir a la docencia una orientación «anarco-sindicalista» e inculcar «la inmoralidad de la manera más laica y grosera». Sobre lo primero, Fraiz afirma desconocer la existencia de tal pedagogía, y en relación con lo segundo advierte que en su historial no existe ninguna amonestación por este u otro motivo, pero aprovecha la ocasión para hacer saber que acerca de su trabajo se han difundido «las más descabelladas fantasías», por las que no se le pregunta, pero de las que, por lo que parece, deseaba

Extalin los hacía caer del techo de la escuela, donde de antemano los había colocado» (f. 66). Ergo, Dios no existe y Stalin, sí.

38 Los informes emitidos en el proceso de depuración profesional eran algo menos agresivos, si exceptuamos el de la Guardia Civil. El cura ecónomo de San Francisco se limitaba a registrar que sus ideas eran antirreligiosas y disolventes, y lo mismo hacía, invirtiendo el orden de los términos, el vecino elegido por el propio sacerdote como representante de los padres de familia; el alcalde le atribuía «ideas anarco-sindicalistas y en este sentido desarrollaba su labor pedagógica», mientras que la Guardia Civil escribía que difundía entre sus alumnos la «inmoralidad» y que su enseñanza era «depravada y funesta» (AGA, 32/32/12882-17).

39 «En su escuela se ensayaban y entonaban toda clase de himnos revolucionarios y en los últimos tiempos se consagraba a verter en el cerebro de sus discípulos los principios de la escuela libre-pensadora, llegando en una recta interpretación de la ortodoxia marxista, a prostituir el corazón de sus discípulos, ya en el aspecto familiar, inculcándoles que solo debe subsistir el acato a la madre, por poder ser el padre cualquier individuo, ya en el afán sectario inculcándoles la negación absoluta de la Divinidad, lo que trataba [de] demostrar mediante vulgares manejos que gravitaban las conciencias de los pequeños, a los que pretendía ver convertidos en iconoclastas propugnadores de la religión [sic para la última parte de la cita]» (f. 102). 
hablar, suponemos que debido al peso que tenían en el sumario de la causa militar:

Por ejemplo: que para negar la existencia de Dios, les repartía caramelos a los niños, diciéndoles que los mandaba Lenin desde Moscú, que era el único Dios y el único Cielo que existían. Y que para explicarles el fenómeno de la maternidad, les hablaba, con toda crudeza, del placer sexual, de la pareja fecundante, y de que nuestros padres no merecen, por tanto, cariño ni respeto alguno, ya que su misión es como una fábrica de hacer chiquillos. Y ¡vamos!, estas y otras cosas, tan ingenuas, que inventa la malévola insidia de algunas gentes, sólo perjudican al propio calumniador: porque, nadie que me conozca, puede creerlas. ¡Tal es la candidez tosca y burda, de su contenido didáctico! Y yo, copiando una célebre frase de Romanones, también diré que «puedo ser travieso, pero no tonto». Y sólo un tonto o un incauto, pueden emplear en su escuela estos procedimientos educativos. ${ }^{40}$

A mí me convence el argumento, que comparto, y al que concedo, en principio, credibilidad, entre otras razones porque en el expediente de depuración nadie demandaba al maestro rebatir el cargo concreto de aplicar una práctica tan efectivamente «tosca y burda» como las anteriormente aludidas para intentar demostrar que Dios no existía. Una práctica que, por lo demás, no encuentra fácil encaje en la imagen que tenemos del «maestro republicano»-al menos en la que yo tengo-, por muy laico que este fuese, y Fraiz sin duda lo era, tanto que en 1930 se adhirió a la Liga Laica Nacional, presidida por Manuel Bartolomé Cossío, con la esperanza de convertirse en el primer maestro gallego que adquiría tal condición. ${ }^{41}$ Pero no deja de ser sorprendente que este tipo de imputaciones apareciese con frecuencia en los expedientes de depuración del magisterio, como he podido comprobar en la investigación que estoy realizando sobre la provincia de A Coruña, y como también sucede en otras latitudes. ${ }^{42}$ Podría ser que formasen parte de una «leyenda negra»

\footnotetext{
40 Expediente de depuración, AGA, 32/12882-17.

41 Garrido Moreira, Víctor Fraiz, 87-88. Firmaba la carta en calidad de ex presidente de las asociaciones de maestros de Ponte Caldelas y Vigo, que eran «los más preciados trofeos de mi vida profesional».

42 Martínez Pereda, Medo político e control social na retaguarda franquista, 79-80; Leonardo Borque López, La represión violenta contra los maestros republicanos en Asturias (Oviedo: KRK Ediciones, 2010), 95-96.
} 
sobre el «maestro republicano» tejida durante la propia República y la Guerra, pero conviene tener presente que en esta figura coexistían maestros y maestras católicos, agnósticos -abundaban entre los que tuvo la oportunidad de tratar Xosé Manuel Cid en los años ochenta del pasado siglo en la provincia de Ourense- y ateos, algunos de los cuales militaban expresamente en contra de la religión, por lo que es posible que en ocasiones utilizasen argumentos ateístas que alimentasen la leyenda. Además, en la memoria familiar del caso que nos ocupa aparece un «artilugio mágico» del que nos da cuenta Emilio Garrido Moreira, advirtiendo que se utilizaba con propósitos lúdicos: Fraiz preguntaba a los niños si querían caramelos, y al decir que sí les hacía saber que debían pedírselos a Dios, y como no aparecían por ninguna parte, los animaba a que probasen con Lenin, activando entonces dicho artilugio para que empezasen a caer caramelos del techo de la escuela... ${ }^{43}$ Si se trataba de un simple juego, debemos convenir que era un tanto rebuscado.

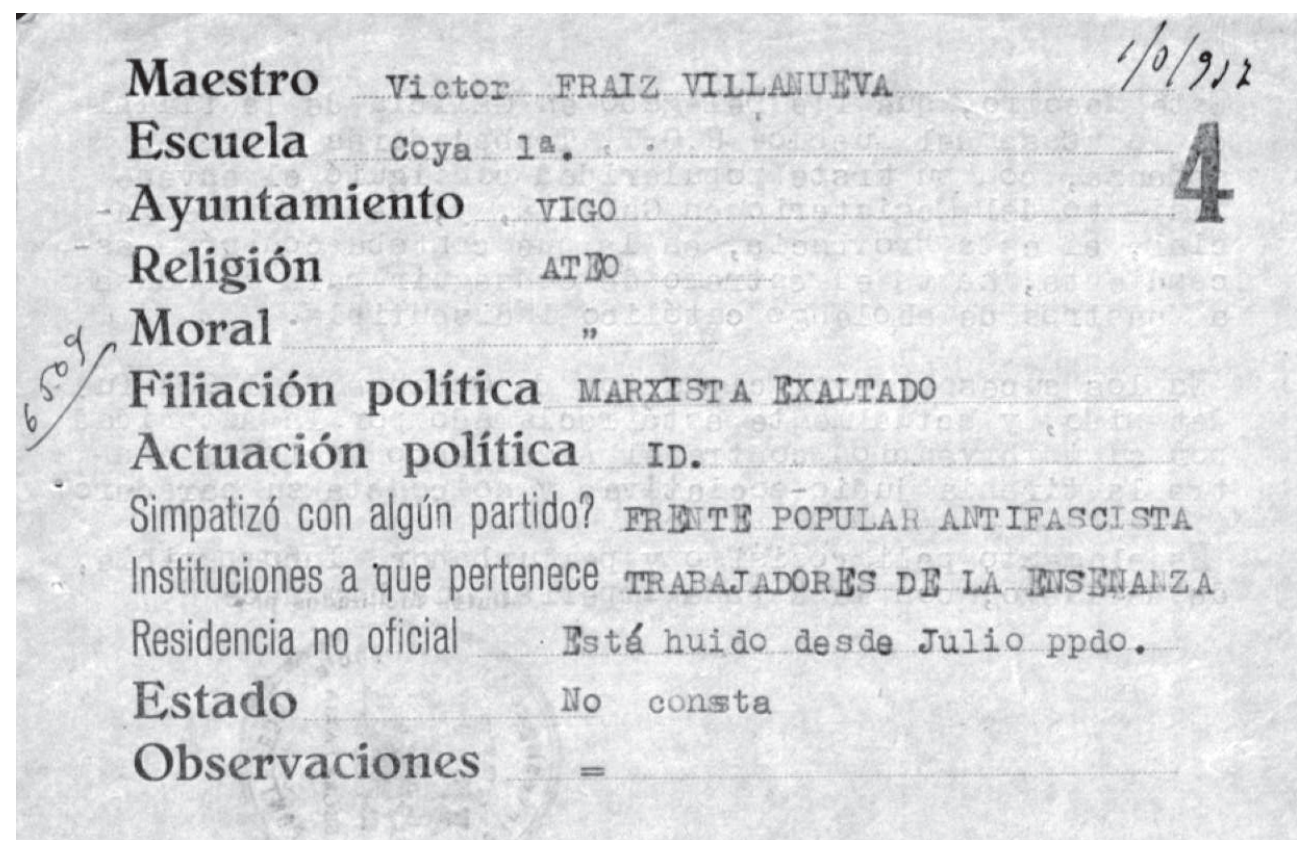

Imagen 4. Ficha policial del expediente de depuración, AGA, 32/12882-17.

43 Garrido Moreira, Victor Fraiz, 108-109. 
Retomando el sumario de la causa militar, Fraiz negó, en sus declaraciones al juez, haber utilizado la escuela para difundir ideas revolucionarias, pues su labor se había centrado en la enseñanza de las materias propias de este nivel educativo, ateniéndose, en lo que a la religión se refería, a las directrices establecidas por el gobierno. Para demostrar que así era solicitó que se convocasen como testigos a algunas personas cuyas declaraciones pensaba que podían favorecerle, como Antonio Mediero y Alfredo Pérez Viondi.

El primero era un maestro que tenía la escuela al lado de la del encartado, y declaró en la vista de la causa que nunca había oído cantos revolucionarios, pero que en la parroquia «se comentaba» que se los enseñaba a los niños, y también que su actuación como maestro era «bastante desastrosa» o «muy mala», pero que él nada sabía con certeza al respecto; lo que sí sabía, por haber asistido a ellos -declaración ciertamente temeraria-, es que en un mitin pronunciado en Coia alabó a la religión y en otro la escarneció. El segundo, teniente coronel retirado de Sanidad Militar y alcalde de Vigo durante la anterior Dictadura, confesó que precisamente por esa circunstancia había tenido alguna «pequeña relación» con el maestro, "pero que nunca llegó a sus oídos ningún comentario respecto a la labor destructora de VÍCTOR FRAIZ en la escuela, cosa que no tiene nada de particular, ya que no se lo permitiría el deponente en su condición de Alcalde monárquico» (f. 117).

El abogado defensor, Justiniano Bayón García, alférez provisional de Infantería, se empleó a fondo -al menos hasta donde las circunstancias lo permitían- en el ejercicio de la función que se le había encomendado. En relación con el extremo que ahora nos ocupa, descalifica a los testigos que prestaron declaración durante la instrucción del sumario, pues el primero, e instigador de todos los demás, Cancelo Miras, tenía enemistad manifiesta con el maestro, y tampoco podía concederse atención a la «fantasía popular» invocada por otros, entre otras razones porque en la hoja de servicios del maestro no existía mancha alguna. La opinión pública valoraba la actuación de este desde una perspectiva exclusivamente política, y no atendía a otras dimensiones, como su afición a la literatura, a la declamación, al canto o a los torneos deportivos. ${ }^{44}$ Sobre

44 El abogado alude aquí a cuestiones sobre las que seguramente le informó el propio Víctor Fraiz, y de las que el maestro deja constancia en el pliego de descargos que remitió a la comisión 
otras acusaciones -se refiere a las perversidades denunciadas por el falangista Del Barrio Lemos- "ni hablar», pues esto «sería hacer de una causa dos razones de penar»(f. 118). Al historiador sí le corresponde aludir, en mi opinión, a esas infamias, o al menos dejar constancia de ellas, pues ponen de manifiesto hasta donde estaba dispuesto a llegar el fascismo para destrozar a sus enemigos.

\section{CONDENA A MUERTE}

En la diligencia de la lectura de cargos, practicada el 14 de julio de 1937, al ser preguntado si quería que se citase a algún testigo o se realizase alguna prueba adicional, Fraiz reclamó que se personasen en el consejo de guerra, además de las dos personas ya mencionadas en el apartado anterior, el médico Cándido Rasilla Salgado y Martín de Vicente Sasiain, que se sumasen a los autos una copia de un folleto en el que figuraba un discurso del procesado ${ }^{45}$ y una tarjeta que le había dirigido su hijo, ${ }^{46}$ y ser sometido a un examen psiquiátrico.

El examen, practicado al día siguiente por el médico forense del juzgado número dos y de la cárcel de Vigo, concluyó con un diagnóstico que seguramente no resultó del agrado del procesado ni de su abogado: el maestro tenía un «temperamento nervioso y ligeramente emotivo, pero sin llegar a los límites de lo patológico, puesto que conserva sus facultades mentales en perfecta integridad funcional y convenientemente

depuradora provincial, donde podemos leer la siguiente descripción de su itinerario profesional: «Nací de una numerosa familia de maestros, en donde todo el árbol genealógico, no tiene más heráldica que la enseñanza, ni más blasón que el Magisterio. Maestro yo, nieto, hijo y hermano de maestros, a esta clase tenía el deber de rendir mis amores y vincular en ella mis ansias incontenidas de justicia y de cultura. Y así, en constante torneo de actividad y en una heroica gesta de lucha y sacrificio, me pasé la vida luchando por la causa del Magisterio y aportando mi óbolo modesto al acervo educativo de la cultura popular: organizando asociaciones de maestros; defendiéndolos de caciques, de malos políticos y de jefes tiranos; organizando reuniones pedagógicas y fiestas escolares; gestionando mejoras en su precaria situación económica; creando batallones infantiles y tropas de exploradores; organizando cuadros artísticos de canto y declamación; fundando revistas literarias; dirigiendo equipos de educación física y deportivos; siendo directivo de varias entidades culturales; escribiendo miles de cuartillas para la prensa diaria y profesional y pronunciando docenas de conferencias culturales en casi todos los pueblos de esta provincia» (AGA, 32/12882-17).

45 Se refería a su discurso sobre el Conde de Gondomar, pronunciado en el marco del homenaje realizado el 25 de julio de 1921 en la villa de Gondomar a Gonzalo Fernández de Córdoba. Fue publicado por Garrido Moreira, Víctor Fraiz, 169-173.

46 La tarjeta no aparece en el sumario. 
regulada[s] por el control de su voluntad y su conciencia, que le permite reconocer y apreciar con exactitud la importancia y el alcance de todos sus actos» (f. 112).

Diferente era el parecer del también médico Cándido Rasillla, que a preguntas de la defensa afirmó haber sido testigo de una «curación que por medio del hipnotismo le practicó el Sr. Gómez Jaime, Cónsul de Colombia» al procesado, y que este se había consultado varias veces con el declarante, lo que le permitía afirmar "que se trataba de un individuo anormal en su estado cerebral»; preguntado por el fiscal, y si bien se abstiene de afirmar, con carácter general, que no fuese responsable de sus actos, sostiene que "puede darse el caso, debido a su impresionabilidad y anormalidades antes indicadas, que de muchas cosas sea irresponsable»; finalmente, y en respuesta al vocal-ponente del consejo, declara que es un «neurótico» (f. 117). Lo mismo hubiese declarado seguramente su mujer, Placeres Castellanos, caso de poder de hacerlo, pues en la causa abierta en 1934 advertía que padecía "neurastenia», por lo que su carácter variaba de un día para otro, y «no cree tenga ideas políticas definidas». ${ }^{47}$

Concluido el interrogatorio de los testigos, se concede la palabra al fiscal, José Pérez Ardá, alférez honorífico del cuerpo jurídico militar, que considera responsable al maestro del delito de adhesión a la rebelión militar y pide para él la pena de muerte. Contrasta esta petición con la realizada por la fiscalía jurídico militar cuando le fue remitida la causa por el auditor de guerra para que realizase la calificación previa, pues para el mismo delito proponía el 8 de julio, una semana antes de la vista, la reclusión perpetua a muerte. Es muy posible que desde alguna instancia se hiciese saber que Víctor Fraiz Villanueva debía ser eliminado, porque las propuestas para Gumersinda y Ricardo -la prisión temporal se concreta en quince años- y para Julio Vilaboa Villar -libre absolución- se mantuvieron inalterables, al menos en este momento procesal.

El abogado, sabiendo que su defendido lo tenía todo en contra, se aferra a la psicología y a la genética para solicitar clemencia al tribunal. Se trataba de un hombre de carácter «excitable» y «amigo de la soledad,

47 AIMNOR, Causa 376/34, f. 10. 
sentimental», «habla solo, ríe y llora con facilidad», algunos de sus familiares sufrían desequilibrios mentales - «un tío suyo murió loco»- y él mismo fue tratado con éxito mediante procedimientos hipnóticos, por lo que merecía, al menos, la atenuante de «enajenación mental incompleta». Quizás todo ello «nos explica su errar continuo de un partido político a otro sin encontrar acomodo", necesitado como estaba de buscar refugio en la política-siempre equivocado, eso sí-. «Esto y sus manifestaciones de canto y deporte con los niños, permite razonablemente creer que a la España naciente podría servirla de veras, máxime tan desengañado de lo anterior». Por lo demás, no existían pruebas de su participación en el atraco y muerte del falangista, y se había entregado voluntariamente a las autoridades (f. 117 v. y 118).

Finalmente, se le da la palabra al procesado, que niega haber intervenido en los sucesos de San Xoán do Monte, circunstancia en la que tampoco hacían especial énfasis las sucesivas instancias judiciales, y presenta un alegato para pedir clemencia. Pues bien, a estas alturas del relato me siento obligado a precisar que, a mi entender, este tipo de alegatos, con independencia de cuál sea su contenido, están amparados por el contexto de subversión e ilegitimidad en el que se inscriben, y suponen una penalidad adicional a las ya padecidas por los represaliados y a las que les restaban por padecer. Decía así:

Hace resaltar que a presencia de la guardia Civil, el Cónsul le prometió que la España de Franco le respetaría la vida, y sacándole ésta no podría trabajar por la Nueva España. Sigue diciendo que el Sr. Viondi [ex alcalde de Vigo] sabe que a los veinte años de edad era maestro, que no hizo daño en sus clases, creando varias Agrupaciones infantiles, tales como exploradores y que los periódicos de la Región reconocían su actuación fuera de la política y que ésta es un $1 \%$ de sus actividades; que es un buen patriota y ruega al Tribunal que no se le condene a muerte, sigue diciendo que tiene 2 hijos enrolados en Falange Española, uno de ellos presta sus servicios en el Polígono de Marín y el otro en Canarias, y por estos dos hijos, en nombre de la España Grande y del General Franco, pide que no se le condene a muerte (f. 118).

Pero en la Nueva España no había espacio para hombres como Fraiz, y así lo afirmaba con contundencia la policía de Vigo: «Incompatible, 
desde luego, con la España Imperial». ${ }^{48}$ La sentencia del tribunal mantuvo las propuestas formuladas por el fiscal en los casos de Víctor, Gumersinda y Ricardo, y transformó la libre absolución de Julio -recordemos que había acompañado al maestro en su entrega a los sublevados- en reclusión perpetua. Nuestro hombre se negará a firmar la notificación reglamentaria de su sentencia, que será ejecutada el 14 de septiembre de 1937. El cadáver fue enterrado en el nicho 36 de la zona cuarta del cementerio de Pereiró (Vigo).

Durante su estancia en prisión fue visitado con frecuencia por sus hijas, Milagros y María Consolación, e incluso por su hijo pequeño, Manolito, aunque Víctor pidió que se abstuviesen de llevarlo a la cárcel, por no ser este un lugar apropiado para los niños. También se relacionaba con sus compañeros, a los que procuraba ilustrar sobre asuntos varios, según testimonia uno de ellos: "Víctor era un home moi culto, e moitas tardes, dende a súa cela, coa mira erguida e sentados nós no chan fronte á súa cela, dábanos charlas de historia, agricultura, etcétera; era un home que, malia a súa situación, miraba o futuro con entusiasmo e dábanos alento e esperanza no porvir».49 Sus últimas cartas las dirigió a su hermano Celso, emigrado en Argentina, y a su compañera, Placeres Castellanos. Al primero le confiesa que había consagrado su vida al ideal de justicia, y que al despedirse de ella se sentía «adorado por mis hijos, idolatrado por mis amigos y admirado por los extraños. El día que Galicia conozca mi muerte, miles de lágrimas empañarán las mejillas y miles de corazones latirán de dolor». A su mujer la esperaba en Pereiró, y aunque le gustaría decirle muchas cosas, las palabras se resistían, pero no importaba, porque «las tumbas de los mártires hablan mucho más ante la Historia que lo que ellos pudieran decir».50

\section{CONSIDERACIONES FINALES}

A diferencia de otros docentes juzgados por los militares sublevados, en cuyos sumarios existen escasas referencias a su trayectoria

\footnotetext{
48 Expediente de depuración, AGA, 32/12882-17

49 Memorias de Manolo Barros, 83.

50 Xesús Alonso Montero, Cartas de republicanos galegos condenados a morte (1936-1948) (Vigo: Xerais, 2009), 358-362.
} 
escolar -en el juicio a que fue sometido Gregorio Sanz García, por ejemplo, este aspecto se incorporó por iniciativa del propio maestro ${ }^{51}-$, en el caso de Víctor Fraiz Villanueva esta dimensión aparece en primer plano. Previamente, en el proceso de 1934, el protagonismo también correspondió a su militancia en la FETE. Leídos ambos sumarios, uno tiene la sensación de que en su persona se quería procesar y condenar a la FETE y a la escuela republicana. Una escuela que para la derecha más extrema ponía en cuestión las «instituciones básicas de nuestra civilización», 52 especialmente si estaba regentada por quienes pugnaban por el "paraíso del proletariado». Y nuestro protagonista constituía uno de los prototipos de los maestros que debían ser eliminados, por lo que estaba condenado de antemano. Él posiblemente lo sabía, y así se lo confesó a su ex cuñado, como este declaró en el sumario: no se entregaría a las autoridades porque «sabía a ciencia cierta que tan pronto lo verificase lo fusilaban» (f. 30 v). Pero aun sabiéndolo, se entregó. Todo parece indicar que lo hizo para salvar la vida de los hijos que aún no le habían asesinado.

\section{Nota sobre el autor}

NARCiso de Gabriel es catedrático de Historia de la Educación de la Universidade da Coruña. Fue director del Departamento de Pedagogía y Didáctica (1993-2005) y decano de la Facultad de Ciencias de la Educación (2005-2012). Es autor de los libros Agricultura e escola. Contra a rutina e o éxodo rural (1989); Leer, escribir y contar. Escolarización popular y sociedad en Galicia (1875-1900) (1990); Escolantes e escolas de ferrado (2002); Arximiro Rico, luz dos humildes (2002, en colaboración con Xosé Manuel Sarille); Ler e escribir en Galicia. A alfabetización dos galegos e das galegas nos séculos XIx e xx (2006); Elisa e Marcela. Alén dos homes (2008, traducido al castellano en 2010); 25 anos de UDC. A Universidade na Coruña e Ferrol (2015); Elisa e Marcela. Amigas e amantes

\footnotetext{
51 Narciso de Gabriel, «Gregorio Sanz, o mestre elocuente», Sarmiento. Revista Galego-Portuguesa de Historia da Educación 22 (2018): 207-234.

52 Una de las preguntas del formulario elaborado por la comisión depuradora de la provincia de A Coruña para indagar la conducta del magisterio decía así: «Si inculcaba o inculta a sus alumnos el respeto a las Instituciones básicas de nuestra civilización, tales como la Patria, la familia, la propiedad, la jerarquía de las clases sociales, etc.»
} 
(2019, publicado el mismo año en castellano) y Xosé María Álvarez Blázquez, mestre republicano. Diario escolar e desterro (2019). Ha colaborado en diversos libros colectivos y publicado artículos en revistas como Sarmiento, Historia de la Educación, Historia y Memoria de la Educación, History of Education y Pedagogica Histórica. Recibió los premios de investigación María Barbeito, Losada Diéguez, Concepción Arenal y el de la Crítica. En la actualidad dirige Sarmiento. Revista Galego-Portuguesa de Historia da Educación.

\section{REFERENCIAS}

Abad Gallego, Xoán C. «Manuel González Fresco: Un "fuxido" entre la realidad y el mito». Boletín del Instituto de Estudios Vigueses 9 (2003): 9-37.

Agulló Díaz, María del Carmen. "Amputar, segar, limpar e purificar: a depuración do maxisterio durante o franquismo». Sarmiento. Revista Galego-Portuguesa de Historia da Educación 21 (2017): 9-30.

Alonso Montero, Xesús. Cartas de republicanos galegos condenados a morte (1936-1948). Vigo: Xerais, 2009.

Beramendi, Justo. De provincia a nación. Historia do galeguismo político. Vigo: Xerais, 2007.

Borque López, Leonardo. La represión violenta contra los maestros republicanos en Asturias. Oviedo: KRK Ediciones, 2010.

Cid Fernández, Xosé Manuel. Educación e ideoloxía en Ourense na II ${ }^{a}$ República. Organización e acción socioeducativa do Maxisterio primario. Santiago de Compostela: Andavira, 2010.

Cid Fernández, Xosé Manuel. «A represión franquista en Ourense: novos argumentos contra a desmemoria na persecución sufrida polo maxisterio». Sarmiento. Revista Galego-Portuguesa de Historia da Educación 21 (2017): 73-99.

Costa Rico, Antón. «Socialismo e educación na Galiza do primeiro terzo do século xx». En IIas Xornadas de Historia de Galicia, editado por Xavier Castro y Jesús de Juana, 135-164. Ourense: Servizo de Publicacións da Deputación Provincial, 1986.

Costa Rico, Antón. Escolas e Mestres. A educación en Galicia: da Restauración á Segunda República. Santiago de Compostela: Xunta de Galicia, 1989.

Costa Rico, Antón. "A "legalidade" dos franquistas: os procesos de depuración. O caso do mestre Víctor Fraiz Villanueva». Sarmiento. Anuario Galego de Historia da Educación 10 (2006): 289-296.

De Gabriel, Narciso de. «Gregorio Sanz, o mestre elocuente». Sarmiento. Revista Galego-Portuguesa de Historia da Educación 22 (2018): 207-234. 
De Gabriel, Narciso. «A represión dos mestres republicanos de Muros». Sarmiento. Revista Galego-Portuguesa de Historia da Educación 23 (2019): 257-289.

De Luis Martín, Francisco. Historia de la FETE (1909-1936). Madrid: Fondo Editorial de Enseñanza, 1998.

De Luis Martín, Francisco. La FETE en la Guerra Civil española (1936-1939). Barcelona: Ariel: 2002.

De Luis Martín, Francisco. La FETE (1939-1982). De la represión franquista a la transición democrática. Madrid: Tecnos, 2009.

Fernández Santander, Carlos. Alzamiento y Guerra Civil en Galicia (1936-1939). Sada: Ediciós do Castro, 2007.

Freixanes, Víctor F. «O Fresco». Memoria dun fuxido. 1936. Vigo: Xerais, 1984.

Galicia bajo la bota de Franco. Santiago: Alvarellos Editora, 2005 (1 ${ }^{\mathrm{a}}$ ed. Paris: Jean Flory, 1936).

Garrido Moreira, Emilio. Víctor Fraiz. Vida e asesinato dun mestre exemplar. Santiago de Compostela: Fundación Luis Tilve, 2002.

Grandío Seoane, Emilio. A Segunda República en Galicia. Memoria, mito e historia. Vigo: Nigratrea, 2010.

Hernández Huerta, José Luis. «La represión franquista de la enseñanza. Fuentes y bibliografía (1975-2007) para el estudio de la depuración del magisterio nacional». Papeles Salmantinos de Educación 11 (2008): 231-266.

Martínez Pereda, Lucio. Medo politico e control social na retaguarda franquista. Vigo: Xerais, 2019.

Memorias de Manolo Barros. Autobiografía dun militante comunista. Santiago: Fundación 10 de marzo, 2006.

Pérez Galán, Mariano. La enseñanza en la Segunda República. Madrid: Biblioteca Nueva, 2011.

Porto Ucha, Anxo Serafín. Historias de vida. O maxisterio pontevedrés na II República, Guerra Civil e Franquismo. Ponteareas: Alén Miño, 2003.

Porto Ucha, Anxo Serafín. Mestras e mestres pontevedreses depurados polo franquismo. Primeiras accións represivas e estudo por concellos no sur da provincia (1936-1942). Ponteareas: Alén Miño, 2008.

Porto Ucha, Anxo Serafín y Raquel Vázquez Ramil. «A depuración do maxisterio primario na provincia de Pontevedra (1936-1942)». Sarmiento. Revista Galego-Portuguesa de Historia da Educación 21 (2017): 31-72.

Quintas Alborés, Elisa. Placeres Castellanos. Vigo: A Nosa Terra, 2008.

Santidrián Arias, Víctor Manuel. Historia do PCE en Galicia (1920-1980). Sada: Ediciós do Castro, 2002).

Soto Fernández, Luis. Castelao, a U.P.G. e outras memorias. Vigo: Xerais, 1984. Terrón, Aida. «Coordenadas del asociacionismo profesional de los docentes. Estado de la cuestión en España». Historia y Memoria de la Educación 1 (2015): 93-130. 
Terrón, Aida y Viñao, Antonio. «Educación, movimiento obrero y sindicalismo (España, siglo XX)». Historia de la Educación. Revista interuniversitaria 37 (2018): 69-114.

Velasco Souto, Carlos F. 1936. Represión e alzamento militar en Galiza. Vigo: A Nosa Terra, 2006. 